\title{
CTLA-4 (+49A/G) Polymorphism and Type-1 Diabetes in Turkish Children
}

\author{
Fatih Çelmeli1, Doğa Türkkahraman2, Deniz Özel3, Sema Akçurin4, Olcay Yeğin5, \\ ${ }^{1}$ Antalya Education and Research Hospital, Department of Pediatric Immunology, Antalya, Turkey \\ ${ }^{2}$ Antalya Education and Research Hospital, Department of Pediatric Endocrinology, Antalya, Turkey \\ ${ }^{3}$ Akdeniz University Faculty of Medicine, Department of Medical Statistics, Antalya, Turkey \\ ${ }^{4}$ Akdeniz University Hospital, Department of Pediatric Endocrinology, Antalya, Turkey \\ ${ }^{5}$ Akdeniz University Hospital, Department of Pediatric Immunology, Antalya, Turkey
}

\section{ABSTRACT}

Objective: To evaluate the contribution of cytotoxic T-lymphocyte antigen-4 (CTLA-4)+49A/G polymorphism to the susceptibility to type-1 diabetes (T1D) in Turkish children.

Methods: A case-control study was designed to include 91 Turkish children with T1D and 99 healthy controls. CTLA-4 (+99A/G) gene polymorphism typing was done by PCR amplification followed by restriction fragment length polymorphism method.

Results: The genotype and allele frequencies of the CTLA-4 (+99A/G) polymorphism in patients with T1D were not different from those in the controls $(\mathrm{p}>0.05)$. The allele frequency of $\mathrm{G}$ was $36.2 \%$ in patients with T1D, and $31.8 \%$ in controls $(p>0.05)$. Additionally, this polymorphism was not associated with the clinical and laboratory characteristics of the patients with T1D ( $p>0.05)$.

Conclusions: Our case-control study suggests that the CTLA-4 (+99A/G) gene polymorphism is not associated with T1D in the Turkish population.

Key words: CTLA-4, polymorphism, type-1 diabetes

Conflict of interest: None declared

Received: 04.12 .2012

Accepted: 23.01 .2013

\section{Introduction}

Diabetes mellitus is a group of metabolic diseases characterized by chronic hyperglycemia resulting from defects in insulin secretion, insulin action, or both. Type-1 diabetes (T1D) is an insulin-dependent form of diabetes with high mortality and morbidity rates, which usually begins in childhood and adolescence. Most cases are primarily due to T-cellmediated pancreatic islet $\beta$-cell destruction, and the patient becomes clinically symptomatic when approximately $90 \%$ of pancreatic beta-cells are destroyed (1). Serological markers of the autoimmune process including islet cell, glutamic acid decarboxylase (GAD), IA-2, or insulin autoantibodies (IAA) are present in $85-90 \%$ of individuals when fasting hyperglycemia is detected (2).

A variety of genetic predisposing factors and contributing factors are known to influence the pathogenesis of T1D. There is some evidence suggesting that the susceptible genes to T1D are associated with amplification of the immune response and rate of progression of the disease. The role of these genes appears to be more important during childhood than during adult life (3). In several studies, it has been shown that more than 40 genetic loci are associated with T1D (4). Many of the susceptibility genes are located within the HLA locus on chromosome 6p21, known as IDDM1 (5). Another 
significant susceptibility locus (IDDM12) maps to cytotoxic T-lymphocyte antigen-4 (CTLA-4) gene region of chromosome 2q33 (6). IDDM12 has also been implicated in systemic lupus erythematosus, autoimmune thyroiditis, celiac disease, and rheumatoid arthritis (7). IDDM12 contains a cluster of T-lymphocyte-regulating genes including CD28, CTLA-4, and inducible co-stimulator (ICOS). CTLA-4 is a member of the immunoglobulin superfamily that is expressed on the surface of activated T-cells and downregulates T-cell function, whereas CD28 enhances T-cell proliferation. Binding of CTLA-4 to the B7 receptor limits the proliferation of T-cells and terminates the ongoing immune response (8). In many molecular epidemiologic studies, CTLA-4 (+49A/G) single nucleotide polymorphism (SNP) that causes a threonineto-alanine substitution in codon 17 has been found to be associated with genetic susceptibility to T1D in several populations, although conflicting data also exist in populations of different ethnic backgrounds (9). The aim of this study was to evaluate the contribution of CTLA-4 $(+49 \mathrm{~A} / \mathrm{G})$ polymorphism to the susceptibility to T1D in Turkish children.

\section{Methods}

Ninety-one unrelated Turkish patients aged between 3 and 19 years with T1D diagnosed in our outpatient clinic were included in the study. The diagnosis of T1D was based on the blood glucose level as per the World Health Organization diagnostic guidelines. Clinical symptoms, absolute insulindependency, presence of diabetes-related autoantibodies (DRA), islet cell antibodies (ICA), GAD antibodies (GADA), and IAA were also considered in the diagnosis. Demographic characteristics, clinical presentations, presence of other autoimmune diseases, HbA1c levels, and diabetic autoantibody positivity at presentation were recorded in all patients.

The control group consisted of 99 unrelated healthy subjects without T1D and known autoimmune disease, living in the same geographical area, and having the same ethnic origin as the patients. The Local Medical Ethics Committee approved the study, and informed consent was obtained from the parent or guardian of each participating subject.

Genomic DNA was extracted from the peripheral blood of individuals using an $\mathrm{MBI}$ Fermentas DNA isolation kit according to the instructions of the manufacturer. Genotyping of polymorphic restriction sites in the CTLA-4 gene exon 1 position 49 which encodes a threonine (GCC) to alanine (ACC) substitution at codon 17 was done by using PCR amplification followed by the restriction fragment length polymorphism (RFLP) method. Amplification of a 162 bp genomic region of CTLA-4 gene was performed by using forward (5'-GCTCTACCTCTTGAAGACCT-3') and reverse (5'-AGTCTCACTCACCTTTGCAG-3') primers described previously. A $0.25 \mu \mathrm{g}$ genomic DNA was amplified in each 25 $\mu \mathrm{l}$ PCR reaction containing $50 \mu \mathrm{M}$ of each dNTPs (Boehringer,
Germany), $2 \mathrm{U}$ of Taq DNA polymerase, $2.5 \mu \mathrm{l}$ of $10 \times \mathrm{PCR}$ buffer, $0.8 \mu \mathrm{M}$ of each primer. The reaction mixture was first heated at $94{ }^{\circ} \mathrm{C}$ for $4 \mathrm{~min}$ and amplification was done for 33 cycles in a PCR thermocycler by denaturation at $94{ }^{\circ} \mathrm{C}$ for 45 $\mathrm{s}$, annealing at $60{ }^{\circ} \mathrm{C}$ for $45 \mathrm{~s}$ and extension at $72{ }^{\circ} \mathrm{C}$ for $45 \mathrm{~s}$ at each cycle.

RFLP analysis was done using FastDigest Bbvl (Fermentas, Germany) in $30 \mu \mathrm{L}$ total volume by mixing: $10 \mu \mathrm{L}$ of PCR products, $1.0 \mu \mathrm{L}$ of Bbvl restriction enzyme, $2.0 \mu \mathrm{L}$ $10 \times$ FastDigest green buffer, and $17 \mu \mathrm{L}$ nuclease-free water. The mixture was incubated at $37^{\circ} \mathrm{C}$ for 10 min followed by heating at $65^{\circ} \mathrm{C}$ for $10 \mathrm{~min}$. DNA fragments were resolved in $2.0 \%$ agarose gels. The $A$ allele does not create restriction site (162 bp), while the $\mathrm{G}$ allele creates restriction site producing two fragments (88 bp and $74 \mathrm{bp}$ ).

\section{Statistical Analysis}

The statistical analyses were performed using SPSS 10.0 software package. Mann-Whitney $U$, chi-square, KruskalWallis and student's t tests as well as one-way ANOVA were used to compare the differences. Quantitative data were presented as mean \pm SD. A p-value of less than 0.05 was considered significant.

\section{Results}

The study was conducted on 91 patients with T1D (39 male, 52 female) aged between 3 and 19 years. Mean age at diagnosis was 8.5 years (range; $1.5-18$ years). Mean followup period was 3.2 years (range; $0.2-18$ years). The control group consisted of 99 unrelated healthy subjects (47 male, 52 female) aged between 9 and 30 years. There was no statistically significant difference between the control and patient groups with respect to gender or age ( $p>0.05)$. Of the patients with T1D, $43(47.3 \%)$ presented with diabetic ketoacidosis (DKA) and 48 (52.7\%) with hyperglycemia (with or without ketosis). T1D was accompanied by an autoimmune disease (Hashimoto's thyroiditis, celiac disease, and vitiligo) in 19 (20.9\%) of the patients. DRA positivity (in at least one of the three autoantibodies) was present in $66.1 \%$ (39/59) of the patients in whom DRAs measurements were performed. Clinical and laboratory characteristics of the patients at diagnosis are presented in Table 1.

As shown in Table 2, the distribution of CTLA-4 genotype and allele frequencies did not differ significantly between patients and controls ( $p>0.05)$. No single genotype or allele was associated with an altered risk for T1D. Forty $(43.9 \%)$ of the patients were heterozygous for $A / G, 38$ (41.8\%) were homozygous for $A$ and 13 (14.3\%) were homozygous for $G$, whereas the corresponding numbers and frequencies of $A / G$, $A / A$, and $G / G$ genotypes in healthy controls were 49 (49.5\%), $43(43.4 \%)$, and $7(7.1 \%)$, respectively. In patients, the allele frequency of $\mathrm{G}$ was comparable to that in the controls $136.2 \%$ vs. 31.8\%, p >0.05).

Clinical features and laboratory findings of the patients at diagnosis in relation to CTLA-4 $(+49 \mathrm{~A} / \mathrm{G})$ genotypes and 
alleles are presented in Table 3. There was no statistically significant difference between the variables (age, gender, presence of DKA, HbA1c level at diagnosis, presence of other associated autoimmune diseases, and DRA positivity) and the CTLA-4 $(+49 \mathrm{~A} / \mathrm{G})$ genotypes and allele frequencies $(p>0.05)$.

Table 1. Clinical and laboratory characteristics of the patients at diagnosis

\section{Characteristics}

Age (yrs) (mean \pm SD)

$11.7 \pm 5.1$

Age at presentation (yrs) (mean $\pm S D)$

$8.5 \pm 4.3$

Gender (male/female) (n)

$39 / 52$

Duration of disease (yrs) $($ mean $\pm S D)$

$3.2 \pm 0.5$

DKA at onset (n)

$43(47.3)$

$\mathrm{HbA1c}\left(\mathrm{mean}_{ \pm} \mathrm{SD}\right)$

$12.9 \pm 4.7$

Autoimmune diseases ( $\mathrm{n}$ )

19/91 (20.9)

DRA positivity

$39 / 59(66.1)$

DKA: diabetic ketoacidosis, DRA: diabetes-related autoantibody

Table 2. Genotype and allele frequencies of CTLA-4 (+49A/G) polymorphism in patients with T1D versus controls

\begin{tabular}{lllll}
\hline $\begin{array}{l}\text { CTLA-4 } \\
\text { variants }\end{array}$ & Patients (\%) & Controls (\%) & OR (95\% Cl) & p \\
A/A & $38(41.8)$ & $43(43.4)$ & $0.93(0.52-1.66)$ & 0.82 \\
A/G & $40(43.9)$ & $49(49.5)$ & $0.80(0.45-1.42)$ & 0.44 \\
G/G & $13(14.3)$ & $7(7.1)$ & $2.19(0.83-5.76)$ & 0.11 \\
A allele & $116(63.8)$ & $135(68.2)$ & $0.82(0.54-1.25)$ & 0.36 \\
G allele & $66(36.2)$ & $63(31.8)$ & $1.22(0.80-1.87)$ & 0.36 \\
\hline Significant if p<0.05, chi-square test & \\
CTLA-4: cytotoxic T-lymphocyte antigen-4, T1D: type 1 diabetes, OR: odds ratio, \\
Cl: confidence interval
\end{tabular}

\section{Discussion}

We investigated the $+49 \mathrm{~A} / \mathrm{G}$ polymorphism because it has been the most widely analyzed CTLA-4 variant in T1D patients from several ethnic populations. In addition, it is the only known SNP that causes an amino acid change (threonine to alanine) and one that is associated with altered protein expression and T-cell activation. Our results do not support the involvement of CTLA-4 gene in the pathogenesis of T1D in the Turkish population. This contrasts with the positive associations that have been reported for the $+49 \mathrm{~A} / \mathrm{G}$ polymorphism in populations including Spanish, French, Korean, Italian, Mexican-American (10), Belgian (11), Japanese (12), Estonian (13), Iranian (14), and Egyptian (15). On the other hand, no association has been reported in many populations including Chilean (16), Chinese and British (10), Japanese (17), Portuguese (18), Brazilian (19), and Azerbaijani (20). These contradictory results can be explained by the genetic heterogeneity among the studied populations, by the different environmental factors involved in the pathogenesis of T1D, by the limitations of the studies or other methodological issues. Moreover, the CTLA-4 (+49A/G) SNP may not be the real disease-associated variant but rather a marker in linkage disequilibrium with the causal variant, and these inconsistent findings may illustrate the variable strengths of linkage disequilibrium in different populations (18).

The distribution of the CTLA-4 exon 1 polymorphism among Asians and Caucasians shows a clear difference. According to a large meta-analysis (9), the pooled frequency of the $G$ allele was $43.3 \%$ among control subjects (by race, frequencies were $55.4 \%, 36.2 \%, 33.6 \%, 20.6 \%$, and $45.2 \%$ among controls of Asian, European, North African/ Middle Eastern, Sub-Saharan African, and Pacific Asian descent, respectively). The overall pooled prevalence of G/G homozygosity was $20.4 \%$ (33.4\%, 12.8\%, 8.9\%, 5.7\%, and $22.3 \%$ in the five racial descent groups, respectively). The overall pooled prevalence of G/A heterozygosity was $44.8 \%(44.1 \%, 46.8 \%, 49.4 \%, 31.2 \%$, and $45.7 \%$ in the five racial descent groups, respectively). Additionally, analysis of

Table 3. Distribution of CTLA-4 $(+49 \mathrm{~A} / \mathrm{G})$ genotypes and alleles in relation to the clinical features of the patients at diagnosis

\begin{tabular}{llllllll}
\hline & A/A & A/G & G/G & $\mathbf{p}$ & A & G & p \\
\hline Male/Female (n) & $16 / 22$ & $18 / 22$ & $5 / 8$ & 0.71 & $16 / 22$ & $23 / 30$ & 0.90 \\
Age (yrs) (mean \pm SD) & $8 \pm 4.5$ & $9.2 \pm 4.3$ & $7.5 \pm 3.8$ & 0.38 & $8.6 \pm 4.4$ & $8.8 \pm 4.2$ & 0.85 \\
DKA (\%) (n=43) & $20(46.5)$ & $18(41.8)$ & $5(11.6)$ & 0.49 & $58(67.4)$ & $28(32.6)$ & 0.33 \\
DRA positivity (\%) (n=39) & $15(38.5)$ & $19(48.7)$ & $5(12.8)$ & 0.73 & $49(62.8)$ & $29(37.2)$ & 0.82 \\
Autoimmune diseases (\%) (n=19) & $7(36.8)$ & $9(47.4)$ & $3(15.8)$ & 0.83 & $23(60.5)$ & $15(39.5)$ & 0.64 \\
HbA1c (mean $\pm S D)$ & $8.6 \pm 2$ & $8.7 \pm 3$ & $9.1 \pm 4.3$ & 0.80 & $8.6 \pm 2$ & $8.8 \pm 3.3$ & 0.54 \\
\hline
\end{tabular}

Significant if $p<0.05$, Kruskal-Wallis and student's t-test

DKA: diabetic ketoacidosis, DRA: diabetes-related autoantibody, CTLA-4: cytotoxic T-lymphocyte antigen-4 
genotypes suggested that $\mathrm{G} / \mathrm{G}$ homozygous individuals are at a 2 -fold higher risk of developing T1D. Our results are concordant with the findings of this meta-analysis in a way that genotype and allele frequencies of the Turkish population investigated in this study are in between those reported for European and Middle East populations.

In some studies, it has been reported that CTLA-4 polymorphisms are associated with the clinical characteristics of patients with T1D. Abe at al (21) reported that $+49 \mathrm{~A} / \mathrm{G}$ polymorphism is associated with ICA512 antibody positivity and with presence of DKA at diagnosis. Balic et al (22) showed that $+49 \mathrm{~A} / \mathrm{G}$ polymorphism could confer a genetic risk for $T 1 D$, particularly with $G$ allele dosage in younger individuals. Their data also suggested that the association of CTLA-4 with T1D is more striking in patients carrying the $G$ allele of $+49 \mathrm{~A} / \mathrm{G}$ polymorphism, with higher episodes of ketoacidosis and higher glycemic levels at diagnosis. However, the results of our study showed no association between CTLA$4(+49 A / G)$ polymorphisms and the clinical characteristics of patients with T1D. Similar results have also been reported by others $(15,18)$.

In conclusion, CTLA-4 $(+49 A / G)$ gene polymorphism was not associated with T1D in the Turkish population studied. However, more studies with a larger study population are needed to confirm these findings.

\section{References}

1. Gepts W. Pathologic anatomy of the pancreas in juvenile diabetes mellitus. Diabetes 1965;14:619-633.

2. Sabbah E, Savola K, Ebeling T, Kulmala P, Vähäsalo P, llonen J, Salmela PI, Knip M. Genetic, autoimmune, and clinical characteristics of childhood-and adult-onset type 1 diabetes. Diabetes Care 2000;23:1326-1332.

3. Field LL. Genetic linkage and association studies of Type I diabetes: challenges and rewards. Diabetologia 2002;45:21-35.

4. Noble JA, Erlich HA. Genetics of type 1 diabetes. Cold Spring Harb Perspect Med 2012;2: a007732.

5. Davies JL, Kawaguchi Y, Bennett ST, Copeman JB, Cordell HJ, Pritchard LE, Reed PW, Gough SCL, Jenkins SC, Palmer SM, Balfour KM, Rowe BR, Farrall M, Barnett AH, Bain SC, Todd JA. A genome-wide search for human type 1 diabetes susceptibility genes. Nature 1994;371:130-136.

6. Nisticò L, Buzzetti R, Pritchard LE, Van der Auwera B, Giovannini C, Bosi E, Larrad MT, Rios MS, Chow CC, Cockram CS, Jacobs K, Mijovic C, Bain SC, Barnett AH, Vandewalle CL, Schuit F, Gorus FK, Tosi R, Pozzilli P, Todd JA. The CTLA-4 gene region of chromosome $2 q 33$ is linked to, and associated with, type 1 diabetes. Belgian Diabetes Registry. Hum Mol Genet 1996;5:1075-1080.

7. Vaidya $B$, Pearce $S$. The emerging role of the CTLA-4 gene in autoimmune endocrinopathies. Eur J Endocrinol 2004;150: 619-626.

8. Alegre ML, Frauwirth KA, Thompson CB. T-cell regulation by CD28 and CTLA-4. Nat Rev Immunol 2001;1:220-228.

9. Kavvoura FK, loannidis JP. CTLA-4 gene polymorphisms and susceptibility to type 1 diabetes mellitus: a HuGE Review and meta-analysis. Am J Epidemiol 2005;162:3-16.
10. Marron MP, Raffel LJ, Garchon HJ, Jacob CO, SerranoRios M, Martinez Larrad MT, Teng WP, Park Y, Zhang ZX, Goldstein DR, Tao YW, Beaurain G, Bach JF, Huang HS, Luo DF, Zeidler A, Rotter JI, Yang MC, Modilevsky T, Maclaren NK, She JX. Insulin-dependent diabetes mellitus (IDDM) is associated with CTLA4 polymorphisms in multiple ethnic groups. Hum Mol Genet 1997;6:1275-1282.

11. Van der Auwera BJ, Vandewalle CL, Schuit FC, Winnock F, De Leeuw IH, Van Imschoot S, Lamberigts G, Gorus FK. CTLA-4 gene polymorphism confers susceptibility to insulindependent diabetes mellitus (IDDM) independently from age and from other genetic or immune disease markers. The Belgian Diabetes Registry. Clin Exp Immunol 1997; 110:98-103.

12. Ide A, Kawasaki E, Abiru N, Sun F, Kobayashi M, Fukushima T, Takahashi R, Kuwahara H, Kita A, Oshima K, Uotani S, Yamasaki H, Yamaguchi Y, Eguchi K. Association between IL-18 gene promoter polymorphisms and CTLA-4 gene 49A/G polymorphism in Japanese patients with type 1 diabetes. J Autoimmun 2004;22:73-78.

13. Haller K, Kisand K, Pisarev H, Salur L, Laisk T, Nemvalts V, Uibo R. Insulin gene VNTR, CTLA-4 +49A/G and HLA-DQB1 alleles distinguish latent autoimmune diabetes in adults from type 1 diabetes and from type 2 diabetes group. Tissue Antigens 2007;69:121-127.

14. Mojtahedi Z, Omrani GR, Doroudchi M, Ghaderi A. CTLA$4+49 \mathrm{~A} / \mathrm{G}$ polymorphism is associated with predisposition to type 1 diabetes in Iranians. Diabetes Res Clin Pract 2005; 68:111-116.

15. Mosaad YM, Elsharkawy AA, El-Deek BS. Association of CTLA-4 (+49A/G) gene polymorphism with type 1 diabetes mellitus in Egyptian children. Immunol Invest 2012;41:2837. Epub 2011 May 26

16. Angel B, Balic I, Santos JL, Codner E, Carrasco E, PérezBravo F. Associations of the CTLA-4 polymorphisms with type 1 diabetes in a Chilean population: case-parent design. Diabetes Res Clin Pract 2009;85:34-36. Epub 2009 Jul 9

17. Awata T, Kurihara S, litaka M, Takei S, Inoue I, Ishii C, Negishi K, Izumida T, Yoshida Y, Hagura R, Kuzuya N, Kanazawa Y, Katayama S. Association of CTLA-4 gene A-G polymorphism (IDDM12 locus) with acute-onset and insulin-depleted IDDM as well as autoimmune thyroid disease (Graves' disease and Hashimoto's thyroiditis) in the Japanese population. Diabetes 1998;47:128-129.

18. Lemos MC, Coutinho E, Gomes L, Bastos M, Fagulha A, Barros L, Carrilho F, Geraldes E, Regateiro FJ, Carvalheiro $M$. The CTLA4 +49 A/G polymorphism is not associated with susceptibility to type 1 diabetes mellitus in the Portuguese population. Int J Immunogenet 2009;36:193-195.

19. Hauache OM, Reis AF, Oliveira CS, Vieira JG, Sjöroos M, llonen J. Estimation of diabetes risk in Brazilian population by typing for polymorphisms in HLA-DR-DQ, INS and CTLA4 genes. Dis Markers 2005;21:139-145.

20. Ahmedov G, Ahmedova L, Sedlakova P, Cinek O. Genetic association of type 1 diabetes in an Azerbaijanian population: the HLA-DQ, -DRB1*04, the insulin gene, and CTLA4. Pediatr Diabetes 2006;7:88-93

21. Abe $T$, Takino $H$, Yamasaki $H$, Ozaki $M$, Sera $Y$, Kondo $H$, Sakamaki H, Kawasaki E, Awata T, Yamaguchi Y, Eguchi K. CTLA4 gene polymorphism correlates with the mode of onset and presence of ICA512 Ab in Japanese type 1 diabetes. Diabetes Res Clin Pract 1999;46:169-175.

22. Balic I, Angel B, Codner E, Carrasco E, Pérez-Bravo F. Association of CTLA-4 polymorphisms and clinicalimmunologic characteristics at onset of type 1 diabetes mellitus in children. Hum Immunol 2009;70:116-120. Epub 2009 Jan 9 